\title{
ANÁLISE DA ACESSIBILIDADE PARA PESSOAS COM DEFICIÊNCIA VISUAL EM TERMINAIS DE ÔNIBUS
}

\author{
MORANO, Raquel Pessoa (1); \\ SANTIAGO, Zilsa Maria Pinto (2). \\ (1) Universidade Federal do Ceará, Mestranda do PPGAU+D \\ e-mail:raquelmorano20@gmail.com \\ (2) Universidade Federal do Ceará I PPGAU+D, Doutora, \\ e-mail:zilsa@arquitetura.ufc.br
}

\begin{abstract}
RESUMO
O presente artigo investiga as condições de acessibilidade para as Pessoas com Deficiência Visual nos Terminais de Ônibus, de acordo com as Normas vigentes e pelos discursos dos participantes in loco. Para isso, foram utilizadas as metodologias: poema dos desejos, percursos comentados, passeio acompanhado e avaliação pós-ocupação.
\end{abstract}

Palavras chave: Deficiência Visual; Acessibilidade; Terminal de Ônibus.

\begin{abstract}
The present article investigates as accessibility conditions for People with Visual Impairment at Bus Terminals, in accordance with current Norms and the speeches of participants in loco. To do this, use as methodologies: poem of desires, commented routes, guided tour and post-occupation evaluation.
\end{abstract}

Keywords: Visual impairment; Accessibility; Bus Terminal.

\section{INTRODUÇÃO}

O rápido crescimento demográfico das cidades brasileiras trouxe consigo várias consequências que provocam a sociedade e o poder público constituído. Entre elas, a carência de acessibilidade urbana, que deve ser considerada de modo abrangente em que todas as pessoas possam se deslocar com segurança e autonomia. Em sentindo mais amplo, a acessibilidade é entendida como equiparação das oportunidades de acesso ao que a vida oferece. (FERNANDES, 2003, p.11).

A carência de acessibilidade afeta a garantia do direito de ir e vir e a inclusão social, que são dois importantes critérios para a plenitude do direito à cidade. Considerando que os deslocamentos humanos são formadores da estruturação intraurbana (VILLAÇA, 1999) e que a circulação na cidade é uma função urbana já reconhecida (Carta de Atenas, 1933), a criação de espaços com ausência de barreiras torna-se uma necessidade para garantir universalização da cidadania (SANTIAGO; DO NASCIMENTO, 2014).

Para chegar a seu destino, as pessoas utilizam diferentes meios de locomoção individual, como: a pé; bicicleta; motocicleta; automóvel, ou, o ônibus, considerado transporte coletivo. É fácil perceber a relação próxima que existe entre os meios "A pé" e "Ônibus", pois, na grande maioria das vezes, é necessário caminhar da origem até o ponto de embarque e do ponto de desembarque até o destino. Percebe-se, então, que a acessibilidade ao transporte 
público vai além de dar condições de acesso ao ônibus, sendo necessário abranger o acesso às edificações, calçadas e vias públicas.

\begin{abstract}
Os sistemas de transporte público nunca estiveram preparados para atender adequadamente a esse segmento social. A infraestrutura urbana e de transportes, na maior parte das vezes, não foi planejada com elementos que facilitassem 0 deslocamento [...] os passeios públicos, acessos a terminais, pontos de parada e rodoviárias, entre outros, sempre foram construídos para atender pessoas adultas, dentro de um determinado padrão médio da população, sem qualquer dificuldade de locomoção. (CARVALHO, 2015, p. 08).
\end{abstract}

Os terminais de transporte público são locais de grande concentração de pessoas e, portanto, necessitam estar aptos a servir a população em toda sua diversidade. Neste sentido, o objetivo deste trabalho é analisar as condições de acessibilidade para pessoas com deficiência visual, tendo como recorte espacial, os Terminais de Integração de Fortaleza: Terminal Antônio Bezerra; Messejana; Parangaba; Papicu e Lagoa e seus entornos. Esses terminais foram escolhidos, pois, segundo dados fornecidos pela Empresa de Transporte Urbano de Fortaleza (ETUFOR), têm o maior fluxo de Pessoas com Deficiência Visual, e por isso, a análise da acessibilidade foi importante para entendermos a situação atual em relação aos parâmetros de inclusão e mobilidade urbana.

Esse artigo se justifica visto que, há algum tempo, devido a fortes reclamações de usuários, bem como denúncias feitas pelo Ministério Público, os terminais de ônibus de Fortaleza - e seus entornos - vêm recebendo, juntamente com reformas, obras de ajuste em relação à acessibilidade. A importância da análise desse equipamento é verificar se a acessibilidade foi posta em conformidade com as Normas e, também, em relação à satisfação dos usuários, mais precisamente, as Pessoas com Deficiência Visual (PcDV). Isto porque a grande maioria dos estudos elaborados na temática da acessibilidade que são desenvolvidos por pesquisadores do campo da Arquitetura e Urbanismo, são voltados para questões de acessibilidade para Pessoas com Deficiência Física. Esse fato demonstra a necessidade de elaboração de critérios de análise e vistorias que abranjam também as outras Deficiências como: Auditiva, Mental e Visual, a fim de aumentar a compreensão da utilização do espaço público e os desafios encontrados por essas pessoas além de auxiliar o planejador para que seu desenho alcance o caráter universal.

Segundo o Censo (2010), 23,9\% da população brasileira possui pelo menos uma das deficiências investigadas: visual; auditiva; motora e mental ou intelectual. A Região Nordeste apresenta a maior taxa de prevalência de pessoas com pelo menos uma dessas deficiências - 26,63\% e no Ceará a taxa é de 27,69\%. Em Fortaleza, existem 2.106.309 pessoas com alguma deficiência (CENSO, 2010), e está em $5^{\circ}$ lugar nacional em relação ao número de Pessoas com Deficiência. A Deficiência Visual aparece como a de maior incidência na população, atingindo 18,6\% da população brasileira. No Ceará atinge 4,5 \% da População e em Fortaleza, 4,8\% da população possui Deficiência Visual. O que implica urgência da necessidade da população para prática de ações voltadas à melhoria da acessibilidade, consequentemente de um fortalecimento de cidadania.

A metodologia de caráter qualitativo e exploratório, com pesquisa de campo, se apoiou na Avaliação Pós-Ocupação - APO (ORNSTEIN, 1995); no Poema dos Desejos (RHEINGANTZ et al, 2009); no Passeio Acompanhado (DISCHINGER, 2000) e nos Percursos Comentados (THIBAUD, 2002).

A APO pode também ser definida como um procedimento que estabelece recomendações a partir de análises técnicas e avaliação de usuários - para aplicação nas etapas do processo de produção e na etapa de formulação de projetos futuros de ambientes construídos, estabelecendo um ciclo de constante de realimentação (ORNSTEIN, 1992; PREISER, 1996). 
Para as análises técnicas, foi desenvolvido um Checklist com critérios de acessibilidade préestabelecidos com base nos princípios do Desenho Universal (PREISER, 2001; CAMBIAGHI, 2007) e, como parâmetros as normas e leis sobre o assunto (NBR 9050/2015; NBR 16537; CEARÁ, 2009). Para análise dos critérios foram elaboradas fichas para transcrever a situação do lugar, com as seguintes opções: ( ) existe, ( ) não existe e espaço para observações. Isso possibilitou um diagnóstico com dados importantes de comparação. Os critérios de avaliação para o entorno foram: calçadas, sinalização e barreiras.

Após algumas visitas para análise dos critérios escolhidos, o modelo de ficha foi alterado. Considerou-se importante verificar o entorno dos terminais, o tipo de piso e seu estado de conservação, pois não basta o equipamento ser acessível internamente, é preciso, também, verificar as condições de acesso ao equipamento. A condição do piso das calçadas foi considerada um dos critérios mais importantes por ser fundamental para a PcDV caminhar em segurança. O piso não adequado, mal assentado, sem manutenção, com buracos, bueiros sem tampa e obstáculos apresenta perigo para todas as pessoas com deficiência, crianças e idosos. Foi, portanto, um dos itens indispensáveis para a análise.

Para os terminais: sinalização, informação e barreiras. Após as visitas, verificou-se que as Pessoas com Deficiência Visual, restringem a sua passagem pelos terminais às plataformas e os acessos, assim, a análise abrangerá a entrada de pedestres e a plataforma.

Para a avaliação dos usuários, foram aplicados os métodos: "Poema dos Desejos", em que os usuários declaram suas necessidades, sentimentos e desejos relativos ao edifício ou ambiente analisado, tendo incentivo inicial a sentença previamente proposta "Eu gostaria que o [edifício/ambiente] ....". Trata-se de um instrumento de livre expressão que apresenta claramente as demandas e expectativas atuais e futuras dos usuários (CASTRO; LACERDA; PENNA, 2004; RHEINGANTZ et al, 2009); "Passeio Acompanhado", desenvolvido por Dischinger (2000) consiste em avaliar as condições de uso do espaço construído através da percepção do usuário em situações reais; "Percurso Acompanhado", desenvolvido por Thibaud (2002) traz o ponto de vista do usuário, sendo dada a palavra ao participante enquanto a rota é percorrida. Assim, foi possível acompanhar a dinâmica que se estabeleceu no cenário proposto, em tempo real, por meio da observação direta e verbalização das experiências vividas e relatadas pelos participantes, proporcionando ao pesquisador responder a problemas de situações complexas vividas pelo usuário no ambiente estudado e na verbalização de suas ações.

A pesquisa contou com o aporte de conteúdo apresentado e debatido na disciplina de Estágio Docência - componente do Programa de Pós-Graduação de Arquitetura, Urbanismo e Design - na disciplina intitulada Desenho Universal - componente da matriz curricular de Graduação em Arquitetura e Urbanismo da Universidade Federal do Ceará. Além da contribuição dos alunos da disciplina que foram a campo e contribuíram com suas análises e vistorias, as autoras contaram ainda com a participação de voluntários que foram acompanhados até os terminais e contribuíram com observações relevantes em relação ao uso dos equipamentos em seu cotidiano.

\section{DISCUSSÃO E RESULTADOS}

Atualmente, Fortaleza possui sete terminais integrados fechados e dois terminais abertos não integrados (Figura 01). A integração possibilita a acessibilidade a vários pontos da cidade com o pagamento de uma tarifa única. A realização da integração é feita pela transferência de uma linha para outra dentro dos terminais fechados. Mais de 1 milhão de passageiros por dia utilizam o Sistema Integrado de Transporte (SIT) que comporta 263 linhas de ônibus regulares e 22 linhas "corujões" (Prefeitura de Fortaleza, 2016). 

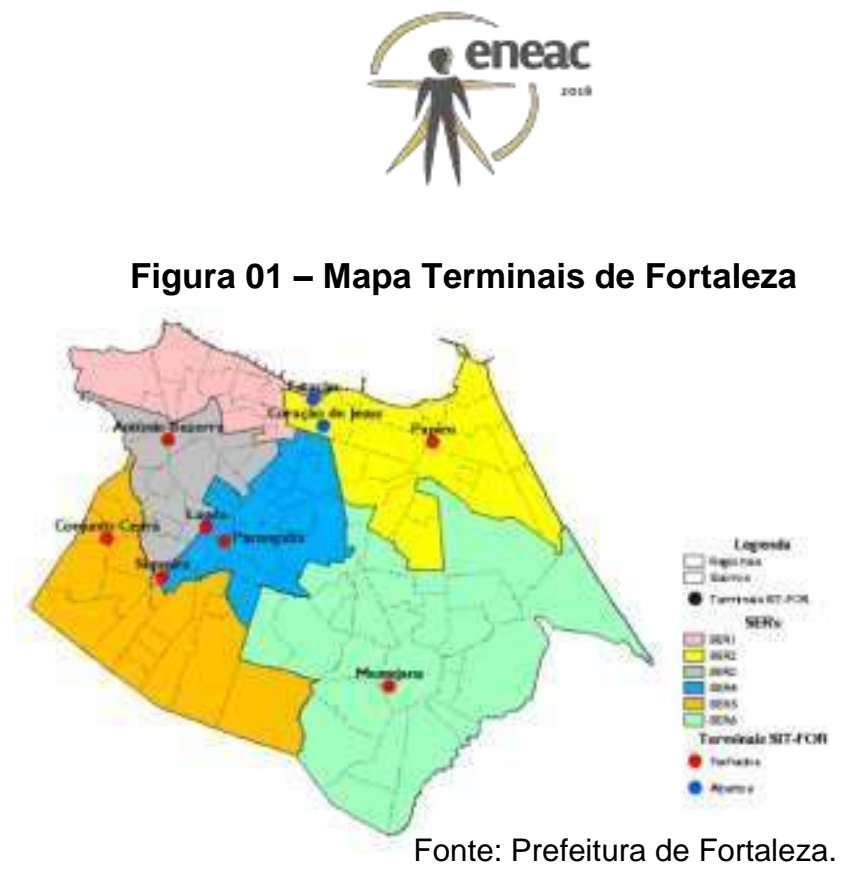

\subsection{TERMINAL DO PAPICU}

O Terminal de Integração do Papicu está localizado na Rua Pereira Miranda, no 80, na Regional II, bairro Papicu (Figuras 02 e 03). É um dos mais movimentados da cidade e sua última reforma foi entregue em 2016.

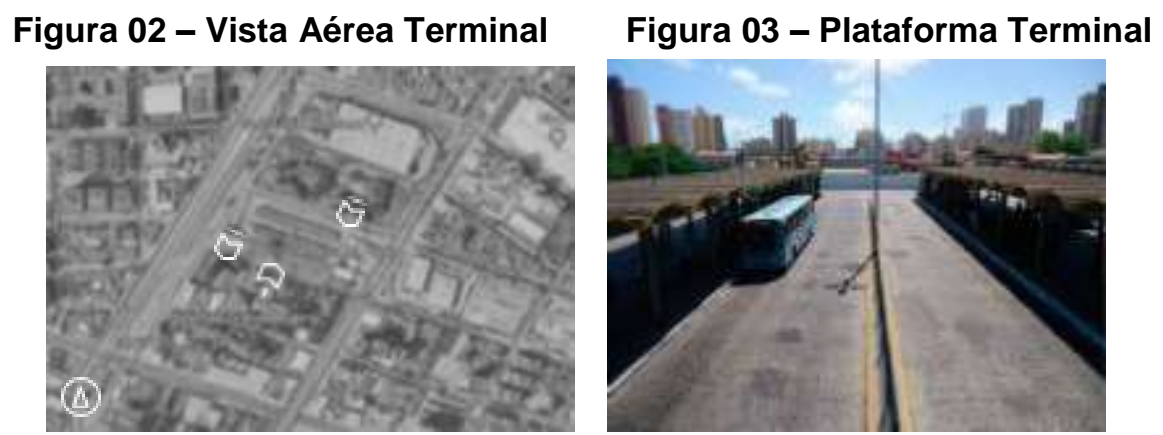

Fonte: Google Earth, editado pelas autoras. Fonte: Prefeitura de Fortaleza, 2016.

O entorno - o equipamento não possui qualquer identificação visual ou numérica para que o edifício possa ser identificado ou qualquer suporte físico tátil que permita que PcDV possam ler e identificar o terminal.

O acesso de pedestres ao Terminal acontece pela Rua Pereira de Miranda, ao lado da saída de ônibus (Figura 02). Nessa rua, a calçada do equipamento e a calçada do outro lado da rua possuem largura para suportar a faixa livre, de acesso e de serviço, porém, apresentam barreiras (Figuras 04 e 05) e má conservação.

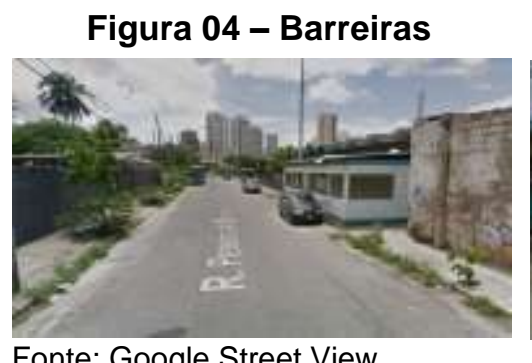

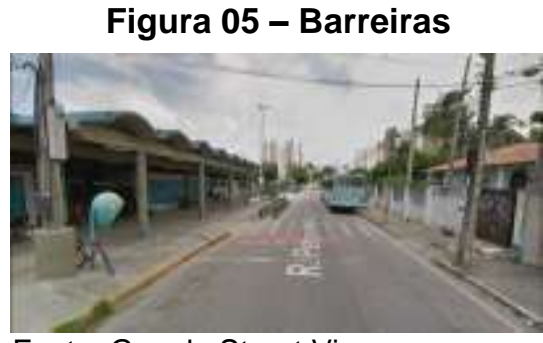

Fonte: Google Street View.

$\mathrm{Na}$ faixa de pedestre percebe-se que foi efetuada a estratégia de redução do percurso da travessia, porém, ao comparar com a NBR 9050/2015, possui alguns equívocos. Dentre eles, o primeiro apontado aqui é como o piso tátil foi aplicado inadequadamente na rampa de acesso (Figuras 06 e 07) segundo a NBR 9050/2015 (Figura 08). E, em segundo, só há rebaixamento em um dos lados da calçada. Durante o percurso com o participante com 


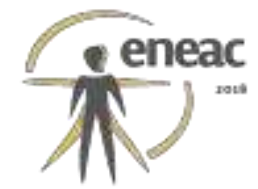

Deficiência Visual, foi relatado que as PcDV utilizam as rampas como referência, para saber onde encontra-se a faixa de pedestre, assim, sem a rampa de um dos lados e sem nenhuma sinalização sonora, não há como a PcDV saber onde deve atravessar.

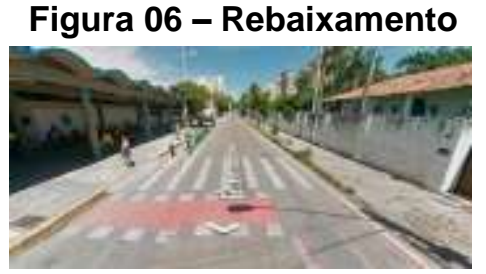

Fonte: Google Street View.
Figura 07 - Piso tátil

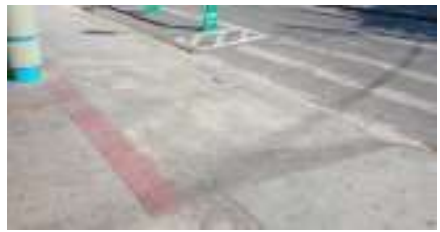

Fonte: Acervo Pessoal

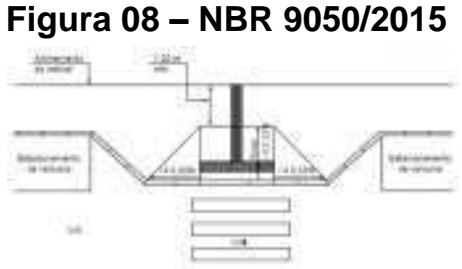

Fonte: NBR 9050/2015.

Ao lado do acesso de pedestre, localiza-se o portão de saída dos ônibus, este não possui sinalização visual ou sonora. A calçada acaba abruptamente e torna-se um lugar aberto onde os ônibus saem a qualquer momento. Esse é um caso de insegurança para as PcDV pois, além de não haver sinalização, foi relatado pelo participante, a não preocupação dos motoristas com os pedestres ao saírem do terminal em alta velocidade (Figura 09).

Acesso - a entrada de pedestre é composta por três portões de passagem, um deles se configura como "portão acessível" e apresenta largura adequada, porém, não se encontra aberto em tempo integral, é necessário auxílio de um funcionário para abri-lo, dificultando e tornando confuso o acesso para as PcDV (Figura 10). A bilheteria (caixa) apresenta acesso dificultado devido a sua localização próximo à catraca tipo "borboleta" e dimensão pequena (Figura 11), além disso, apresenta um peitoril alto inacessível aos cadeirantes e pessoas de baixa estatura.

Figura 09 - Acesso Ônibus

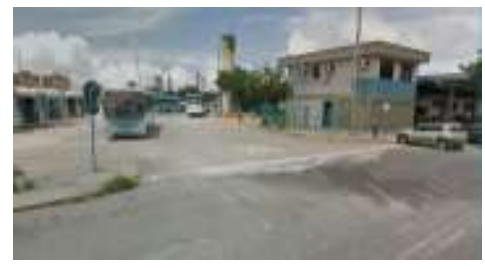

Figura 11 - Esquema Bilheteria

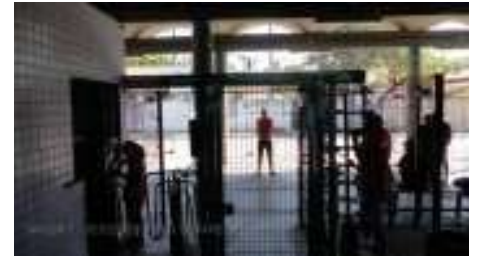

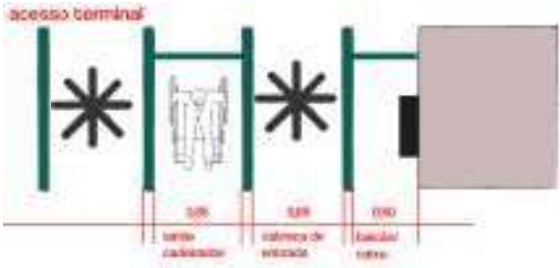

Fonte: Acervo Disciplina Desenho Universal, 2017

A sinalização é um dos fatores importantes para as PcDV, embora haja piso tátil no lado externo do terminal, em alguns pontos, não estão aplicados de acordo com as diretrizes da NBR 16537/2016 e, também, não apresentam o contraste recomendado pela Norma (Figura 12). Internamente, não existe piso tátil e nem rota acessível. Em relação a essa ausência, o participante relata que perde a autonomia e necessita sempre pedir ajuda a funcionários nas plataformas.

Não há mapa tátil e, a comunicação é feita por meio de placas, as quais em algumas situações não apresentam contraste (Figura 13) ou tamanho de letra que possibilite a leitura de uma pessoa com baixa visão (Figura 14), excluindo as pessoas com deficiência visual parcial ou total dessa comunicação. O participante relata que a falta de comunicação tátil não possibilita o entendimento pleno do equipamento.

Figura 12 - Piso Tátil

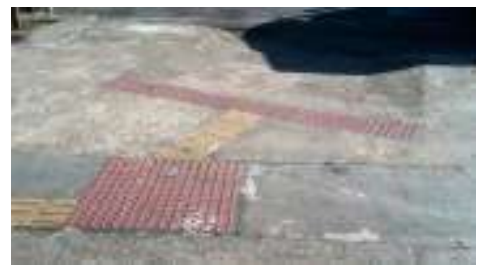

Figura 13 e 14 - Sinalização

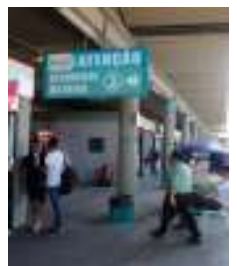




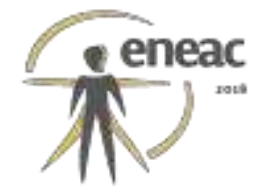

De acordo com a NBR 9050/2015 - item 5.1.3: "A informação deve ocorrer através do uso de no mínimo dois sentidos: visual e tátil ou visual e sonoro". No terminal, não há uso de dois sentidos para comunicação. Na plataforma há apenas placas visuais indicando o número dos ônibus e entradas preferenciais (Figura 15), porém, existe um serviço eficaz de funcionários que estão dispostos a ajudar as PcDV e conduzi-las ao seu destino. $O$ participante fala que sempre quando vai ao Terminal do Papicu é favorecido pela a ajuda desses funcionários e, que por conta disso, se sente seguro e confortável (Figura 16).

Em relação ao mobiliário, foi visto que existem telefones públicos que são considerados como obstáculos suspensos, por não ser possível serem identificados com uso da bengala por PcDV e, por estarem em uma área de trânsito de pedestres (Figura 17).

\section{Figura 15}

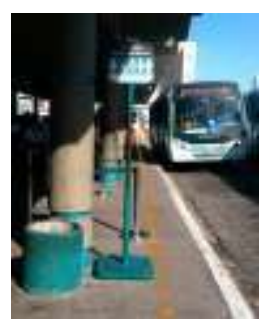

Figura 16 - Funcionário

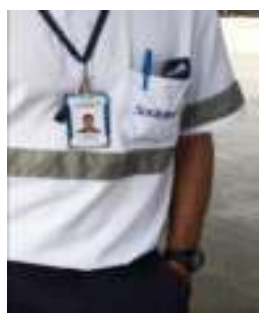

Figura 17 - Telefone Público

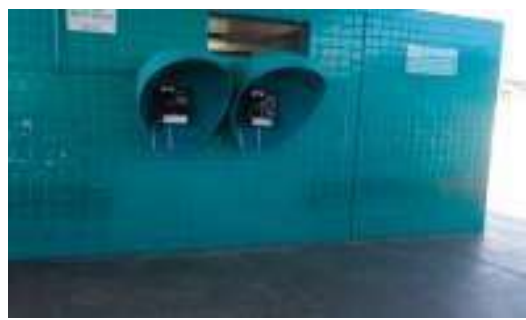

Fonte: Acervo Pessoal.

\subsection{TERMINAL DO ANTÔNIO BEZERRA}

A estrutura original do terminal foi inaugurada em 1 de julho de 1992 pelo ex-prefeito da cidade Juraci Vieira de Magalhães. O Terminal passou por ajustes e adaptações para trazer modernidade e conforto à população e teve sua primeira etapa entregue em 2014.

Localiza-se próximo a uma via expressa de fluxo intenso de veículos de diferentes portes, motocicletas, carros, ônibus e caminhões, a Av. Mister Hull. O terminal é margeado por espaços de circulação, tanto de pedestres quanto de veículos. O edifício conta com dois acessos para pedestres, nas vias menos movimentadas, e dois acessos para ônibus (Figuras 18 e 19).

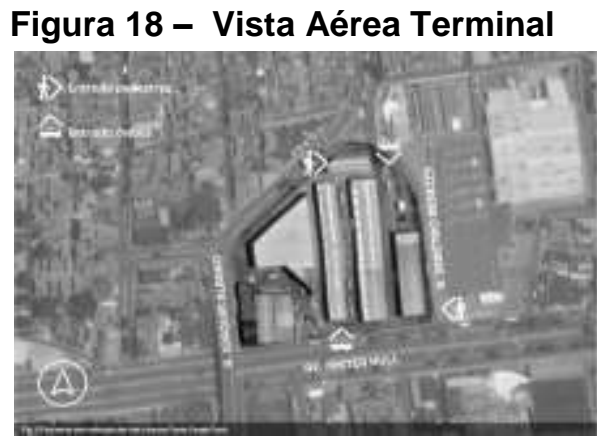

Figura 19 - Plataforma Terminal

Fonte: Google Earth, editado pela autora. Fonte: Prefeitura de Fortaleza, 2016.

O entorno - as calçadas do equipamento apresentam faixa livre, de acesso e serviço como sugere a NBR 9050/2015. Na entrada do terminal pela Rua Demétrio Menezes, observa-se a presença de faixa de pedestres e o rebaixamento da calçada, mas não há, para as PcDV, o piso tátil que o direciona até a faixa de pedestre e o piso tátil de alerta como recomenda a NBR 9050/2015 e a NBR 16537/2016 (Figuras 20, 21 e 22). 


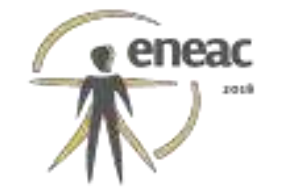

Figura 20 - Diretriz

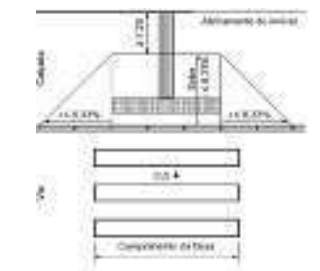

Fonte: NBR 9050/2015
Figura 21- Faixa de travessia

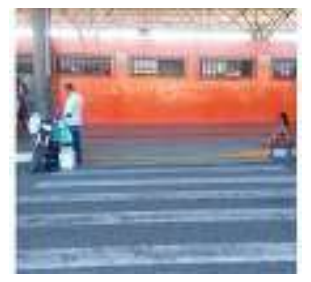

Fonte: Acervo Pessoal
Figura 22 - Falta Piso direcional e alerta

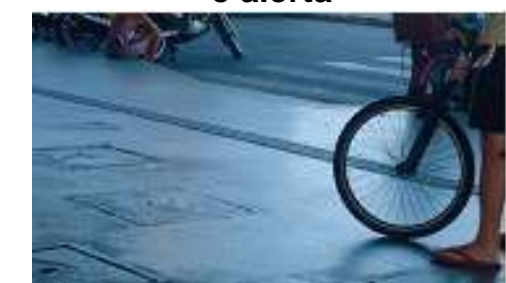

Fonte: Acervo da Disc. Des. Universal, 2017.

Outra incompatibilidade com as diretrizes da NBR 16537/2016 é em relação às cores do piso tátil e de alerta (Figuras 23 e 24). Os pisos utilizados são: industrial e intertravado e, por apresentarem cor cinza, os pisos táteis apresentam coloração equivocada em relação à tabela. Esse fator é importante para as pessoas com baixa visão, pois, muitos deles não conseguem distinguir determinadas cores e, por isso, não conseguem diferenciar relevos, desníveis e imperfeições no piso (Figura 25).

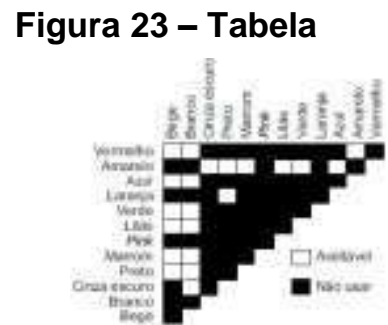

Fonte: NBR 16537/2016.
Figura 24 - Contraste

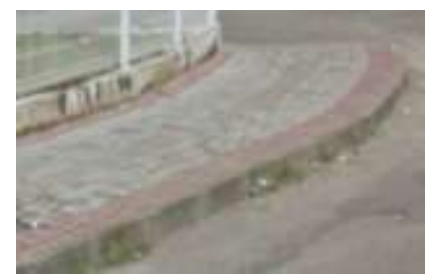

Fonte: Google Street View.
Figura 25 - Piso Tátil degradado

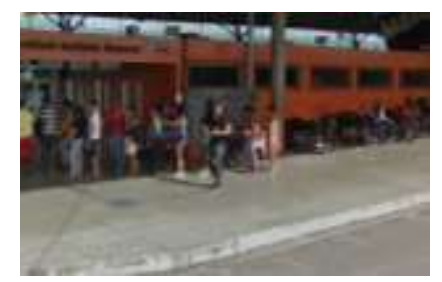

Fonte: Google Street View.

Acesso - Na Avenida Mister Hull e na rua Demétrio Menezes as calçadas são bruscamente interrompidas devido aos acessos de ônibus, não apresentando faixa de pedestre, rebaixamento de calçada e qualquer recurso de alerta. Foi observado que os ônibus, nesse local, não respeitam os transeuntes que se arriscam ao atravessar ali (Figuras 26 e 27). $\mathrm{Na}$ avenida Mister Hull, há presença de comércio informal localizado nas esquinas e, por isso, força a passagem do pedestre pela via, no caso da PcDV esse tipo de situação é de extremo perigo e insegurança (Figura 26). Na rua Demétrio Menezes, a calçada termina e a PcDV fica sem orientação física, nem sonora (Figura 27).

Na rua Joaquim Albano, não há faixa de pedestres para o acesso ao terminal, a calçada não possui sinalização tátil - presente apenas na bilheteria (Figura 28 ) - e, há comércio informal ao longo de toda a calçada, formando barreiras e tornando o ambiente perigoso para as PcDV e intransitável para as Pessoas que usam cadeira de rodas (Figura 29).

Figura 26

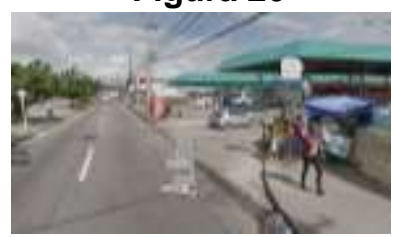

Figura 27

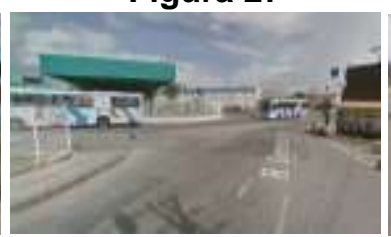

Figura 28

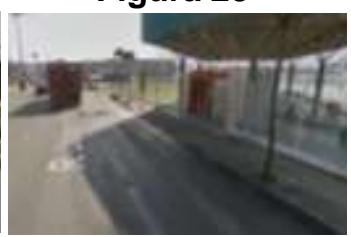

Figura 29

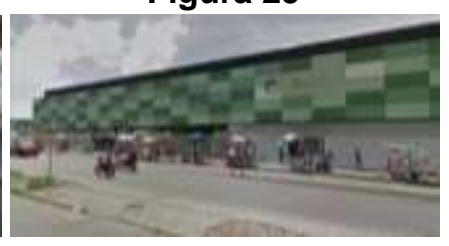

Fonte: Google Street View.

A sinalização - a sinalização tátil está aplicada de forma inadequada em alguns lugares e, em outros sem continuidade. A ausência de sinalização sonora também é comentada como uma falha pelo participante, pois, nas travessias perde sua autonomia, precisando contar com a ajuda de outras pessoas.

As entradas de pedestres são compostas por cinco portões de passagem, das quais uma se configura como um "portão acessível". O Terminal apresenta as mesmas dificuldades, em relação ao acesso de Pessoas com Deficiência, que o Terminal do Papicu. (Figura 30). O terminal apresenta piso tátil, indicando uma rota acessível de entrada e de saída, e dispõe 


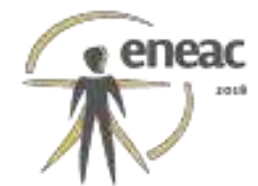

de um funcionário na entrada, o qual se coloca a serviço para qualquer usuário que necessite de um auxílio (Figura 31).

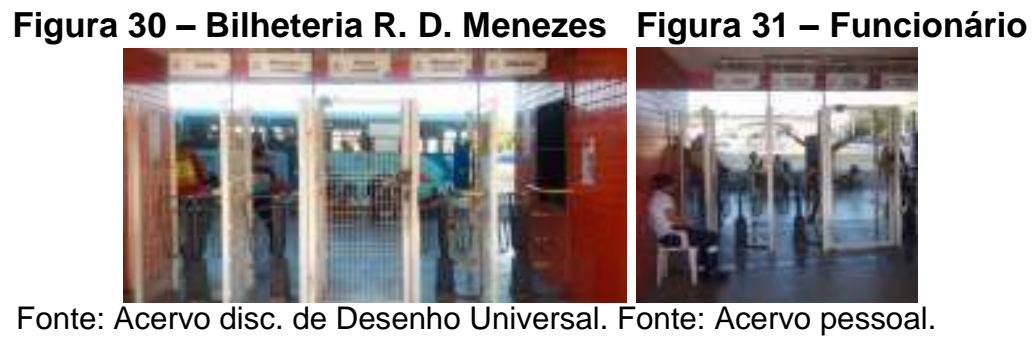

As plataformas que dispõem de área preferencial de espera (Figuras 32 e 33). Ambas possuem em suas bordas piso tátil de alerta, porém, encontram-se equivocados em relação as suas cores e, também, posicionados próximo a obstáculos (Figuras 34, 35 e 36). A sinalização que comunica a rota do ônibus se encontra em altura elevada dificultando a leitura (Figura 32). A sinalização de identificação está adequada (Figura 33) embora para a PcDV é difícil identificar sem auxílio de terceiros.

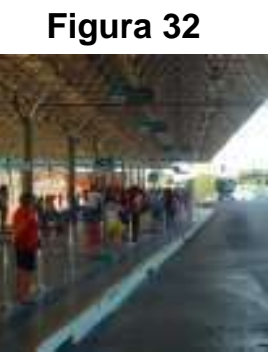

Figura 33

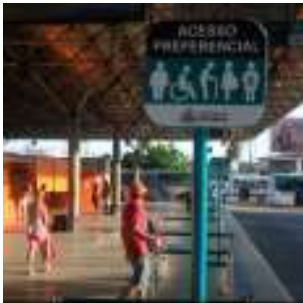

Figura 34

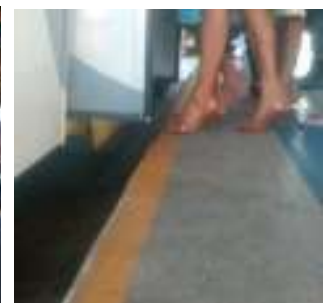

Figura 35

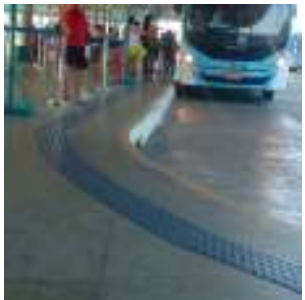

Figura 36

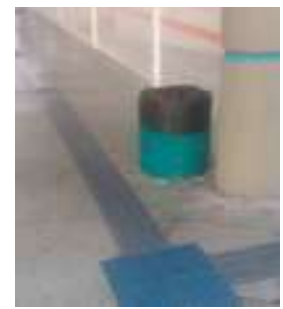

Fonte: Acervo disciplina de Desenho Universal, 2017

\subsection{TERMINAL DE MESSEJANA}

Inaugurado em 1992, atualmente, encontra-se em obras de expansão (Figuras 37 e 38).

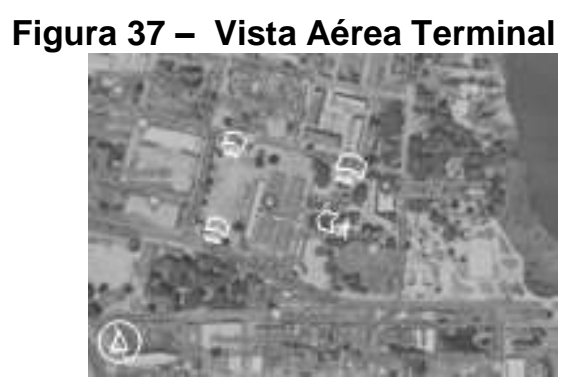

Fonte: Google Earth, editado pelas autoras

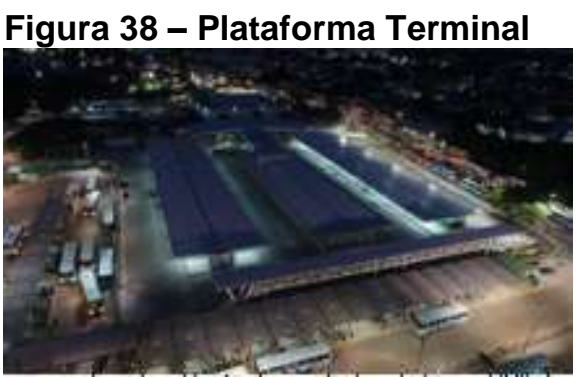

Fonte: Prefeitura de Fortaleza, 2017

O Entorno - as ruas Santa Clara de Assis e Taquatiara apresentam calçadas com largura favorável para passeio, apesar disso, existem barreiras na faixa de passeio e não apresentam piso tátil. $\mathrm{Na}$ rua Taquatiara uma parte do piso é de pedra portuguesa considerado pelo participante como "o pior piso" pois, há irregularidades por conta do mal assentamento. Não tivemos acesso à rua Granja Castelo pois, estava em obras.

A calçada da Av. Jornalista Tomaz Coelho encontra-se com irregularidades, devido às obras do terminal, como: calçada estreita; barreiras; ausência ou degradação de piso e ausência de proteção para circulação de pedestre (Figuras 39, 40 e 41). 


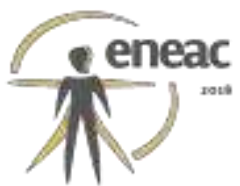

Figura 39 - Entorno

Figura 40 e 41 - Calçada degradada

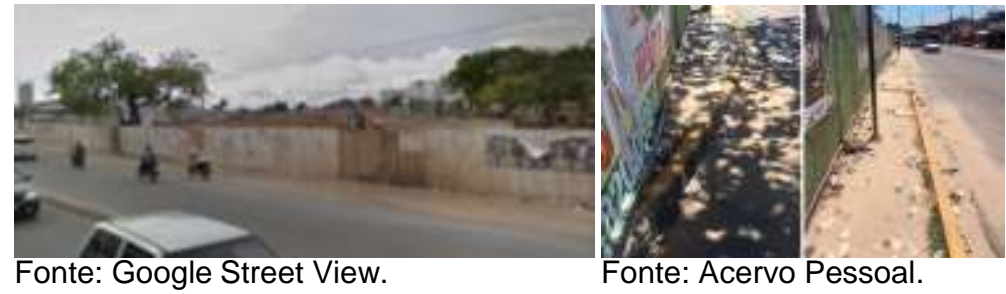

O participante, ao andar nesse trecho, diz que sente insegurança, principalmente, em relação à proximidade com os carros e pelo piso ser irregular. A falta de certeza do que estava por vir o deixa aflito e fez com ele parasse diversas vezes para entender o que estava na sua frente. Ao passar no trecho de entrada e saída de ônibus o participante ficou confuso, interpretou erroneamente o espaço, ele entendeu que estava atravessando uma rua. Depois de explicada a situação, ele falou que deveria haver uma sinalização sonora e, também, rampas para os usuários de cadeiras de rodas (Figuras 42, 43 e 44).

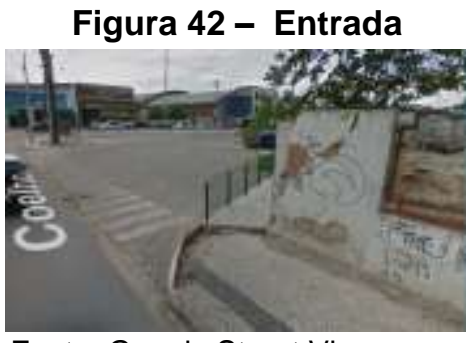

Fonte: Google Street View.
Figura 43 - Saída

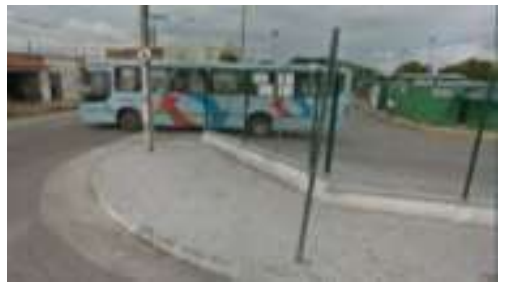

Fonte: Google Street View.
Figura 44 - Entrada e Saída

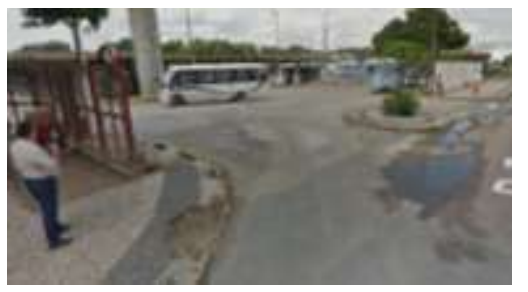

Fonte: Google Street View.

O Acesso de pedestre ao Terminal acontece pela Rua Taquatiara. Para chegar até a bilheteria, é preciso atravessar uma praça, sem nenhuma sinalização e informação (Figura 45). A bilheteria é equipada por diversas catracas de corpo inteiro, com dimensão de $0,60 \mathrm{~m}$, não permitindo a entrada $\operatorname{PcD}$ (Figura 46). $O$ acesso destas pessoas acontece por um portão lateral, sendo necessário auxílio de funcionários (Figura 47).

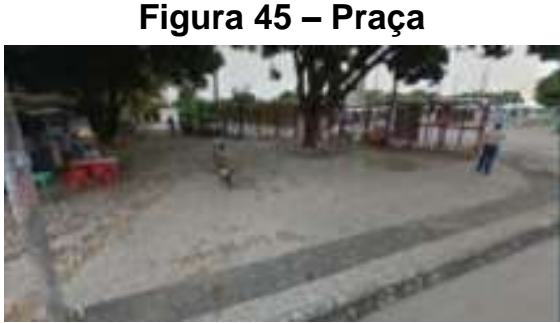

Fonte: Google Street View.
Figura 46 - Bilheteria

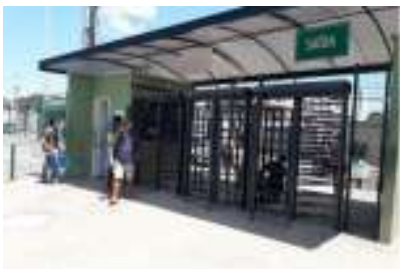

Fonte: Acervo Pessoal
Figura 47- Porta Lateral

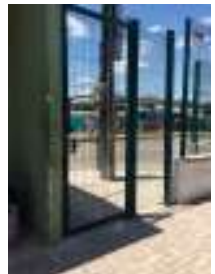

Fonte: Acervo Pessoal

O participante relata que todas as vezes que precisa entrar no terminal pelo acesso de pedestre, procura sair de casa com antecedência, pois, esse sistema é lento e, a catraca convencional o deixa confuso e, também, já o machucou.

A pavimentação interna é toda de piso intertravado. A faixa de pedestre que liga uma plataforma à outra é elevada e garante um percurso confortável para os pedestres, porém, não há piso tátil nem sinal sonoro, dificultando a orientação da PcDV (Figuras 48 e 49). Não há presença de piso tátil em todo o equipamento. 


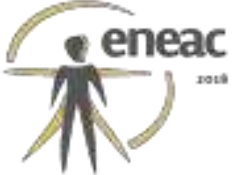

Figura 48 - Faixa Elevada

Figura 49 - Faixa de Pedestre
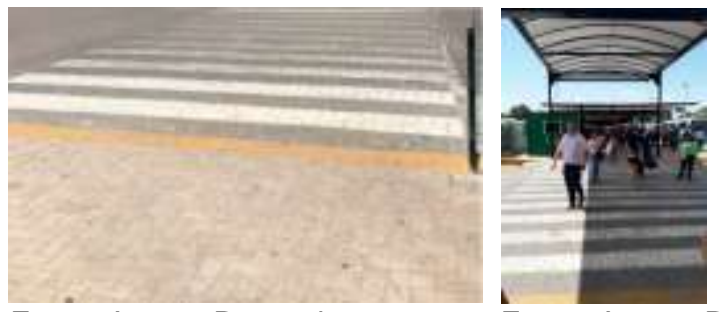

Fonte: Acervo Pessoal

Fonte: Acervo Pessoal

\subsection{TERMINAL DA PARANGABA}

O Terminal se localiza ao lado do Shopping Parangaba, possui acesso na Rua Eduardo Perdigão e Avenida Carlos Amora. Há, também, um acesso pela estação do MetroFor e pelo próprio shopping (Figuras 50 e 51).

Figura 50 - Vista Aérea Terminal

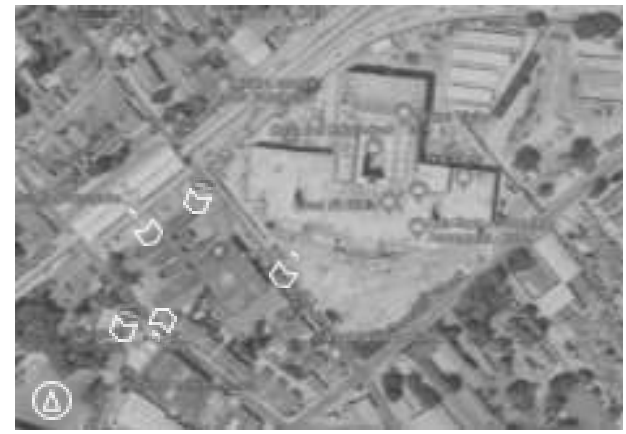

Fonte: Google Earth, editado pela autora.
Figura 51 - Plataforma Terminal

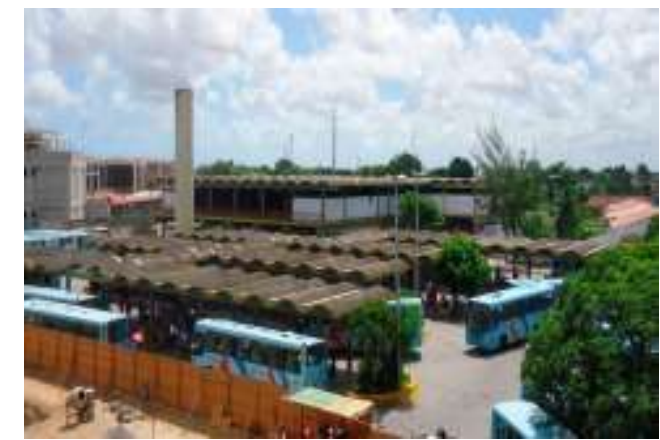

Fonte: Prefeitura de Fortaleza, 2017.

O entorno - foi observada a ausência de: faixas de pedestre; rebaixamento de calçadas; semáforos para pedestres com sinais sonoros e visuais. Os passeios apresentam estreitamentos e presença de obstáculos (Figuras 52 e 53). Existe uma passarela, que segundo o participante, é um alívio quando existe esse auxílio, pois, se sente seguro e protegido longe dos carros (Figura 54).

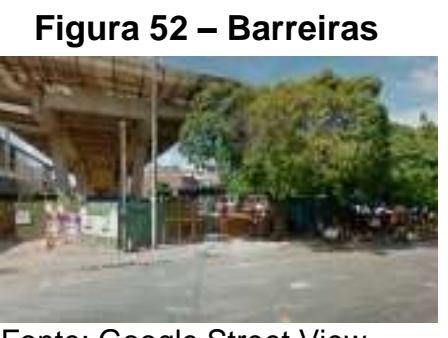

Fonte: Google Street View.
Figura 53

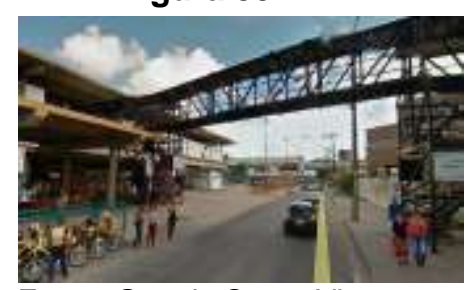

Fonte: Google Street View.
Figura 54 - Passarela

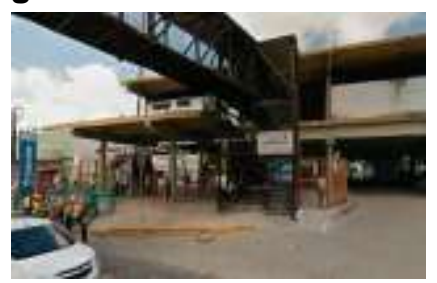

Fonte: Google Street View.

Barreiras - Na parte interna do terminal não há piso tátil, ao invés disso, foi pintado para sinalizar o desnível, apesar de auxiliar os usuários com baixa visão, as PcDV total são prejudicadas (Ver Figuras 55 e 56). Em todo o terminal existem mobiliários sem sinalização de alerta (Ver Figuras 57, 58 e 59). 

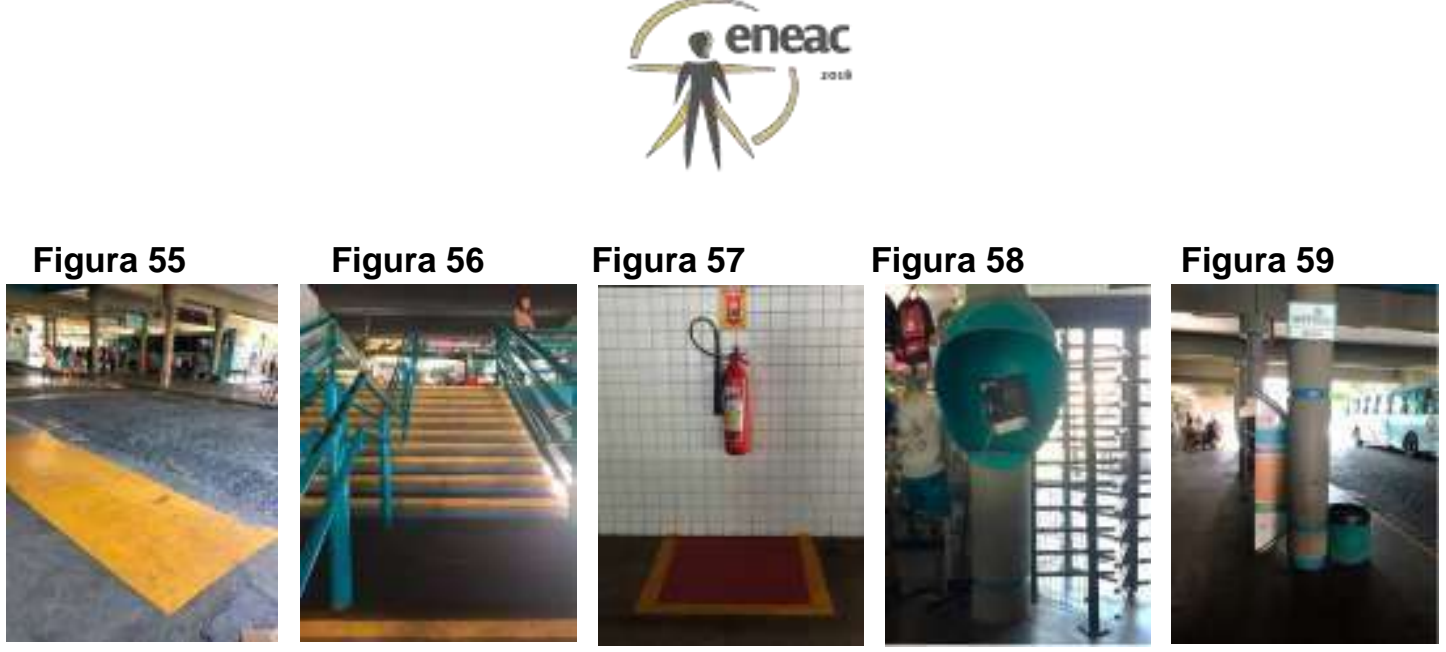

Fonte: Acervo Pessoal

\subsection{TERMINAL DA LAGOA}

O Terminal da Lagoa é um terminal urbano da cidade de Fortaleza, localizado no bairro da Parangaba e, passou por uma reforma em 2016. (Ver Figuras 60 e 61).

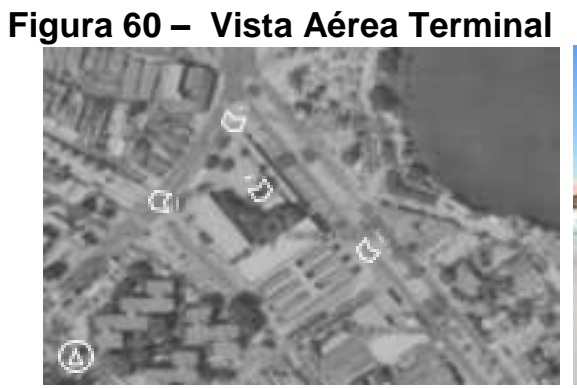

Fonte: Google Earth, editado pela autora.

\section{Figura 61 - Plataforma Terminal}

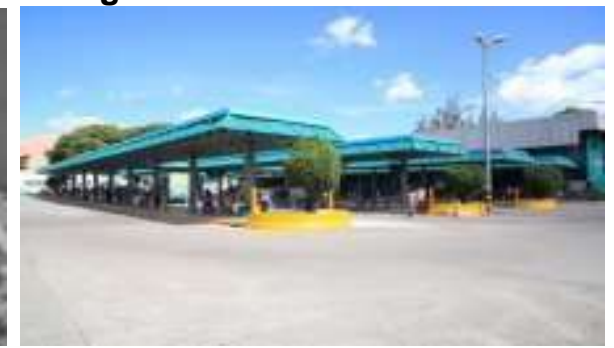

Fonte: Prefeitura de Fortaleza, 2017.

O entorno - Nas calçadas foi identificado irregularidades no piso e falta de manutenção. Há algumas áreas estranguladas por elementos urbanos (Figuras 62, 63 e 64). Há interrupção da calçada no acesso de ônibus. (Figuras 65 e 66).

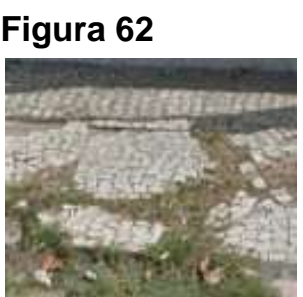

Fonte: Acervo pessoa

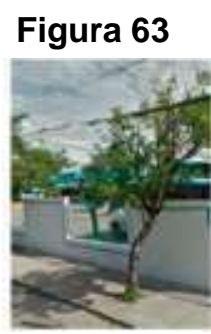

Fonte: Google Street View
Figura 64

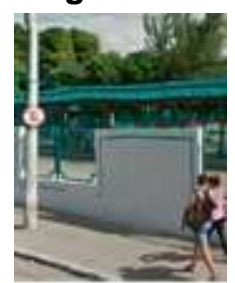

Fonte: Acervo Pessoal

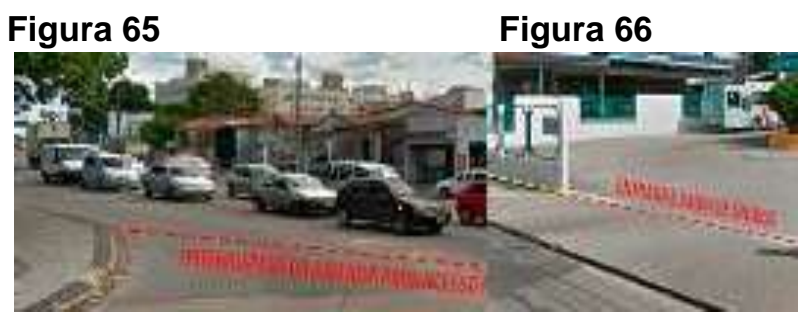

\section{CONSIDERAÇÕES FINAIS}

Os cinco terminais avaliados, ainda que com reformas recentes, não apresentam acessibilidade plena. A falta de sintonia entre normas e práticas é vista nesses equipamentos e impede as PcD de exercerem cidadania. Além disso, a acessibilidade é tratada como um problema exclusivo de um grupo social com soluções técnicas específicas, que quase sempre se constituem de soluções posteriores, fora do contexto do planejamento cotidiano, sem de fato resolverem questões sociais mais graves. A acessibilidade não deveria ser considerada um problema a resolver em comissão ou grupo de trabalho específico, mas consideradas logo nas primeiras fases da tomada de decisões e recebendo devida importância e atenção, incluindo todas as pessoas e eliminando os fatores de exclusão presentes em várias instâncias da sociedade.

O "Poema dos Desejos" foi aplicado em cada participante ao final do percurso, e em síntese, o que foi mais citado em seus desejos foi o desejo por uma acessibilidade plena, não só no terminal onde estava, mas também, em toda a cidade. Outro ponto citado pela maioria foi a 


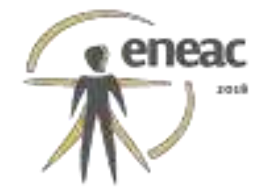

da importância da sinalização sonora nos percursos em geral. Uma das coisas que foi mencionada por todos, foi a do respeito das pessoas em relação à sua característica e, o quanto uma pessoa disponível a ajudar resolve quase que todos os problemas relacionados ao medo e insegurança de andar no espaço público.

Por serem uma porcentagem pequena da população, são tratadas como se não fizessem parte da sociedade, ocasionando em um fator de exclusão social em que muitas pessoas sofrem com as limitações do ambiente. Não apenas as PcD, mas idosos e crianças também são afetados com a inadequação do espaço público às suas necessidades. Apesar de todas as normativas que asseguram a livre locomoção, essa população continua sendo negligenciada pelos órgãos públicos e, também, pela sociedade que apresenta barreiras atitudinais.

\section{REFERÊNCIASBIBLIOGRÁFICAS}

ASSOCIAÇÃO BRASILEIRA DE NORMAS TÉCNICAS. Acessibilidade a edificações, espaços e equipamentos urbanos. Rio de Janeiro, 2015.

ASSOCIAÇÃO BRASILEIRA DE NORMAS TÉCNICAS. Acessibilidade - sinalização tátil no piso Diretrizes para elaboração de projetos e instalação. Rio de Janeiro, 2016.

CAMBIAGHI, S. Desenho Universal: métodos e técnicas para arquitetos e urbanistas. São Paulo: Editora Senac São Paulo, 2007.

CARVALHO, C. H. R. Políticas de Melhoria das Condições de Acessibilidade do transporte urbano no Brasil. IPEA - Rio de Janeiro, 2015.

CASTRO, Jorge; LACERDA, Leonardo; PENNA, Ana Cláudia. Avaliação Pós-Ocupação - APO: saúde nas edificações da FIOCRUZ. Rio de Janeiro. FIOCRUZ, 2004, 116p.

DISCHINGER, Marta. Designing for alll senses: Accessible spaces for visually impaired citizens. 2000. 260f. Thesis (for the degree of Doctor of Philosophy) - Department of Space and Process School of Architecture, Chalmers University of Technology, Göteborg, Suécia, 2000.

FERNANDES, Julieta Cristina. A acessibilidade do idoso em Uberlândia: desafios ao pensamento da cidade inclusiva. Dissertação de mestrado - Programa de Pós-Graduação em Geografia da Universidade Federal de Uberlândia. 2003.

GOVERNO DO ESTADO DO CEARÁ. Guia de Acessibilidade: Espaço Público e Edificações. Elaboração: Nadja G.S. Dutra Montenegro; Zilsa Maria Pinto Santiago e Valdemice Costa de Sousa. Fortaleza: SEINFRA-CE, 2009.

IBGE - INSTITUTO BRASILEIRO DE GEOGRAFIA E ESTATÍSTICA. Censo Demográfico 2010.

Base de dados Sidra. Rio de Janeiro: IBGE, 2010.

ORNSTEIN, Sheila Walbe; BRUNA, Gilda Collet; ROMÉRO, Marcelo de Andrade. Ambiente Construído e Comportamento: a Avaliação Pós Ocupação e a qualidade ambiental. São Paulo, FAU USP/Studio Nobel/FUPAM, 1995.

PREISER, W. F.; VISCHER, J. C.; WHITE, E. T. (Orgs.) Design intervention: toward a more humane architexture. New York: Van Nostrand Rheinhold, 1991.

RHEINGANTZ, Paulo A., et al. Observando a Qualidade do Lugar: procedimentos para a avaliação pós-ocupação. Rio de Janeiro: Coleção PROARQ/FAU/UFRJ, 2009.

SANTIAGO, Zilsa Maria Pinto; DO NASCIMENTO, Raquel Martins. Avaliação das Condições de Microacessibilidade física na Avenida Bezerra de Menezes Pós-Transfor. In: Anais VI Eneac, 2014.

THIBAUD, Jean-Paul. Regards en action. Ethnométhodologie des espaces publics. Bernin: A la Croisée, 2002.

VILLAÇA, Flávio. Espaço Intra-Urbano no Brasil. São Paulo: Ed. Studio Nobel: FAPESP: Licoln Institute, 1998. 